\title{
0 ÚTIL, O SAGRADO E 0 MAIS-QUE-SAGRADO NO XANGÔ DE PERNAMBUCO
}

\section{Roberto Motta \\ Universidade Federal de Pernambuco - Brasil}

Resumo: $O$ sagrado e o útil encontram-se intimamente associados no Xangô de Pernambuco. O processo de iniciação coincide largamente com a busca da cura, enquanto os sacrifícios são ao mesmo tempo bons para rezar e para comer. Não existe portanto, ao contrário do que poderia pretender uma interpretação demasiadamente literal da sociologia da religião de Durkheim, uma separação radical entre o sagrado e o profano. Há entretanto, na experiência religiosa do Xangô, um momento em que o sagrado paira acima de toda análise funcional, transformando-se desta maneira no mais-que-sagrado, que transparece na festa e no transe extático. E é dessa experiência transcendente, implicando na comunhão emocional do grupo de culto, que surge a identidade mais íntima de cada fiel.

Palavras-chave: cura, religiões afro-brasileiras, sacrifício, Xangô.

Abstract: The sacred and the utile are found closely associated in the "Xango de Pernambuco". The process ofinicialization largely coincides with the search of cure, while the sacrifices are both good to pray and to eat. Thus there isn't a radical separation between the sacred and the profane, what a literal interpretation of the Durkheim's sociology of religion could intend. However, in the religious experience of Xangô, there is a moment when the sacred means more than all the functional analysis, becoming, this way, the more-than-sacred, what appears in the party and in the static trance. So it's from this transcendent experience, involving the emotional communion of the cult group that emerges a closer identity of each faithful people.

Keywords: Afro-brazilian religions, cure, sacrifice, Xangô. 


\section{Introducão}

Sem querer afastar-me do espírito da sociologia durkheimiana da religião, inclusive do princípio básico de que a experiência religiosa se encontra na raiz da vida social, pretendo demonstrar, neste artigo, a imbricação do sagrado e do útil no Xangô do Recife. ${ }^{1}$ Efetivamente não há separação entre a busca de alívio para as aflições individuais, compreendendo principalmente a busca da cura, e o processo de iniciação a essa religião. De maneira análoga, pode-se dizer do sacrifício de animais, ${ }^{2}$ no qual se encontra a essência da liturgia do Xangô, que é, ao mesmo tempo, bom para rezar e bom para comer. ${ }^{3}$ Mas pode-se também constatar, nessa religião, fenômenos, como o transe extático, ${ }^{4}$ que superam toda consideração de utilidade ou função: é o domínio do mais-que-sagrado. Aí também nos encontramos em terreno durkheimiano. É dessas situações, com a fusão de consciências que acarretam, que surge a identidade mais profunda dos fiéis.

\section{Iniciação e cura}

Não existe provavelmente religião que não seja, de um modo ou de outro, terapêutica, ou que não signifique resposta à aflição, a qual, em última

1 Para uma descrição geral do Xangô de Pernambuco, que, como se sabe, representa uma variante regional do Candomblé, pode-se 1er Ribeiro (1978) e Motta (1982).

2 O sacrifício é cuidadosamente evitado na maior parte dos trabalhos relativos às religiões afro-brasileiras, talvez por medo de dar idéia de uma religião bárbara ou primitiva. Entretanto Ramos (1940), Herskovits (1958), Bastide (1960), Santos (1976) e Wafer (1991) dedicam-lhe algumas páginas. Antes de meus próprios escritos sobre o assunto (Motta, 1988, 1991a) penso que só La Porta (1979) havia feito dele o tema central de um trabalho.

3 Uso a expressão bom para comer baseado em Lévi-Strauss (1962), o qual parece atribui-la a Malinowski. Por analogia, falo também em bom para rezar.

${ }^{4} \mathrm{O}$ transe extático do Xangô parece-me essencialmente diferente do transe verbal que caracteriza tanto o Catimbó (que compreende o culto dos caboclos, dos mestres e de outras entidades, apresentando também algumas afinidades com a Macumba carioca), como a Umbanda, esta, como se sabe, fortemente influenciada pelo espiritismo kardecista. Note-se ainda que, diferentemente destas duas formas de religião popular brasileira, nas quais prevalece a consulta verbal às entidades incorporadas por curandeiros ou médiuns, a consulta aos orixás faz-se essencialmente pelo jogo de búzios. Esta regra certamente tem exceções. O caráter silencioso (à parte, bem entendido, de muita música e de determinadas exclamações do próprio devoto) do transe no Candomblé-Xangô foi também destacado por James Wafer (1991, p. 62): “The orixás are African aristocrats. [...] When they descend into 'matter' they keep their mouths and eyes closed. [...] Generally the orixás do not talk though I have occasionally seen them whispering instructions to the drummers at a festival.” Sobre as variedades do transe afrobrasileiro pode-se consultar Motta (1991b).

Horizontes Antropológicos, Porto Alegre, ano 4, n. 8, p. 168-181, jun. 1998 
análise, decorre da contingência do ser humano, hoje aqui, amanhã em nenhum lugar... Há portanto a resposta religiosa aos grandes problemas existenciais, o que não exclui que a religião se ocupe com a aflições do quotidiano, que representam, por assim dizer, o troco em miúdo dos valores ontológicos. O que é tanto mais verdadeiro do Xangô de Pernambuco ou do Candomblé da Bahia, quanto em vão se procuraria, nesses cultos, "uma concepção da vida decorrente de uma tomada de posição conscientemente significativa e unificada” (Weber, 1995, p. 203), ou uma doutrina da salvação, ou a idéia de uma "vida que começa com a morte", tal como pretende a tradição cristã. De fato, eles se encontram essencialmente voltados para a solução dos problemas concretos da vida neste mundo.

Se, folheando um desses manuais que os babalorixás do Xangô e do Candomblé às vezes escrevem para instrução de seus discípulos, prestarmos atenção às passagens dedicadas ao jogo dos búzios (que constitui o primeiro passo no processo de iniciação), ficaremos sem dúvida impressionados com a importância que assumem as questões de saúde, amor, dinheiro, emprego, etc. Até talvez três ou quatro décadas atrás, o Xangô do Recife (do mesmo modo que o Candomblé da Bahia) atraía sobretudo as pessoas que, encontrando-se em crise, já o conheciam graças a sua tradição cultural, quase sempre associada com certas origens sociais e étnicas. Hoje em dia, em ligação com o que tenho chamado desetnização das religiões afro-brasileiras, ${ }^{5}$ seu apelo estendeu-se a toda a sociedade, sem distinção de cor nem de origem racial.

Mas não esperemos tampouco encontrar ritos de cura, diferentes ou independentes de outros ritos. É o conjunto da religião que possui valor terapêutico. ${ }^{6}$ E esse conjunto se exprime num conceito fundamental, que é a obrigação, o dever, o sacrifício devido aos santos, ou antes, a tal ou qual santo em particular, sob a forma da imolação de animais, ou do dom, que não é letal mas que não deixa de também ser sangrento, da própria pessoa do fiel. Todos os outros atos do culto levam ao sacrifício ou dele derivam. Mas, como veremos mais adiante, os santos logo repartem com seus devotos as ofertas que destes recebem.

A atitude fundamental do filho-de-santo parece-me bem exemplificada pela história de Creuza, a qual, já faz alguns anos, contava-me o seguinte:

5 Sobre essa desetnização ver Motta (1994).

6 É o que fica bem evidente da leitura de Williams (1979). 
Sou filha de Oxum, o senhor sabe, mas meu segundo santo é Xangô.

Desde o tempo que fiz meu santo eu nunca me esqueci de dar obrigação a Oxum, mas me descuidei de Xangô. O finado Zé Romão, que era meu pai-de-santo, me avisou "cuidado com o couro". Ele tinha razão. Um dia desse, quando eu me acordei, eu estava com os dedos do meu pé esquerdo dormentes. Foi Seu Malaquias, irmão de Zé Romão (que já tinha morrido) que jogou [os búzios] para mim. Era mesmo castigo de Xangô. Eu tive de ir ao [hospital] Pedro II e os médicos cortaram os dedos de meu pé. Umas semanas depois foi toda a minha perna esquerda que foi embora. É por isso que eu estou aqui nesse terreiro. Vou dar uma obrigação completa a Xangô e vou renovar meu bori e meu amassi.

A obrigação de Creuza compreendeu nove bichos de quatros patas (caprinos, ovinos e suínos) e 40 galináceos. Ela também repetiu sua iniciação. Pois a busca da cura, além dos sacrifícios, requer que o fiel se assimile a seu modelo sobrenatural. É como se, sem ter deixado de ser sacrificante, ele também se transformasse em vítima oferecida aos orixás, o que, em contrapartida, permite a manifestação do Santo através das aparências, dos gestos, da dança e do transe do homem.

A iniciação, nos terreiros do Recife e de Salvador, começa pelo jogo dos 16 búzios (diloguns), o qual, pelo menos em teoria, só deve ser praticado por um pai-de-santo (ou uma mãe-de-santo) com sete anos de "feito" (iniciado), tendo já recebido o decá, isto é, passado por uma consagração suplementar que o habilita a gerar os seus próprios filhos. O objetivo central do jogo divinatório é conhecer qual é o santo do consulente, o dono da cabeça daquela pessoa, e quais sacrifícios esta deve ofertar. Efetivamente, quando consultamos o Manual do Sítio, ${ }^{7}$ ou qualquer outro documento do mesmo gênero (muitos deles, em versões muitas vezes resumidas, encontram-se publicados como parte da vasta literatura afro-brasileira de divulgação), ${ }^{8} \operatorname{logo}$

\footnotetext{
Trata-se de um caderno manuscrito, cheio de rubricas rituais, utilizado no Sítio, que é sem dúvida o terreiro de maior prestígio e possivelmente de maior antigüidade no Recife. O Sítio, como outros terreiros no Recife e em Salvador, é particularmente orgulhoso de sua autenticidade nagô.

8 Esta literatura, que enche muitas estantes e prateleiras nas livrarias do Brasil, nunca foi devidamente estudada. Seus autores muitas vezes tiveram acesso a trabalhos eruditos sobre temas afro-brasileiros e, deste jeito, antropólogos e sociólogos acabam por exercer influência muitas vezes determinante sobre a prática ritual. Entre os autores mais influentes desse gênero literário encontra-se o pernambucano José Ribeiro de Souza (que muitas vezes assina apenas José Ribeiro), com muitos trabalhos publicados, sem menção de data, pela Editora Espiritualista, do Rio de Janeiro.
} 
percebemos que não há oráculo que não termine recomendando sacrifícios e sugerindo iniciação.

Esta última implica num processo bastante longo e complicado. Pareceria que cerimônias originárias de vários grupos ou subgrupos étnicos e de diversas épocas tenham se acumulado no Xangô e no Candomblé. E os ritos -basta pensar no preço dos ingredientes - são caros, o que serve para afastar uma boa parte dos candidatos potenciais, que ficarão em estado de minoridade religiosa, mas sem por isso serem barrados das danças nem proibidos de cair em transe.

Se os recursos do devoto forem limitados, ele poderá limitar-se a um pequeno dom, um ou dois frangos ou mesmo o jerimum dos indigentes, na espera de melhores dias. Se, ao contrário, ele tem possibilidade, ele oferecerá, depois do jogo, o ebori, palavra na qual se reconhece o iorubá ebo ori ou bo ori, isto é, o comer da cabeça. Não procuremos, no Xangô e no Candomblé, a concepção de uma alma espiritual, imortal, separada ou separável do corpo. Esse dualismo, judeu-cristão, platônico, tomista, cartesiano, leibiniziano ou como quer que seja, simplesmente não tem sentido para os afro-brasileiros. Para eles, a alma é muito concretamente o on, que representa a cabeça visível e tangível do indivíduo.

Trata-se portanto de oferecer à Cabeça e, através da Cabeça, ao orixá que é o seu dono, um presente composto de tudo que pode ser comido e bebido (“tudo que a boca aceita”), peixe, carnes de vários bichos, frutas, bolos e bebidas de toda qualidade, mas sempre de acordo com as preferências de cada santo. Com a ocasional exceção de uma ou duas aves, nada se mata em cima da cabeça do devoto durante o ebori. As carnes nele incluídas são compradas no mercado.

Notemos que os ministros deste ritual não são apenas o pai e mãe-de-santo do fiel, mas toda a congregação afro-brasileira. E então, quaisquer que sejam as restrições que se queira fazer a certos detalhes da sociologia de Durkheim (1985, p. 547), estamos aqui diante de "uma das formas da refeição moral que é o objeto principal do culto positivo”. Cada iniciado eleva os pratos com as ofertas até a cabeça do devoto. Através dos alimentos estão oferecendo suas próprias cabeças, isto é, suas almas. A identidade do neófito vai surgir do reconhecimento que a comunidade lhe oferece.

Passa-se em seguida ao amassi, também denominado, de maneira mais corriqueira, lavação da cabeça. Na verdade o amassi consiste em lavar-se a 
cabeça do devoto muito bem lavada com água misturado ao sumo de certas folhas - é este líquido que representa o amassi propriamente dito - e com um sabão especial, sabão da Costa. De acordo com a opinião comum dos filhos-decanto (provavelmente influenciados pela concepção cristã do batismo), é aí que se situa o momento essencial e irreversível da iniciação. O amassi imprime um caráter indelével e cria relações sociais indestrutíveis, das quais a principal é a que se estabelece entre o neófito e o pai ou mãe-de-santo que foi o principal oficiante da cerimônia.

O amassi também nos interessa por causa do seu caráter explicitamente terapêutico. Já o termo que o designa outra coisa não significa, em sua língua fon original (e não exatamente iorubá), que remédio. Ora, os fiéis do Xangô e do Candomblé não gostam de abstrações. O que implica que não têm idéia de uma pureza espiritual separada do bem estar corporal. O amassi é portanto uma terapia, baseada no poder curativo das folhas que o compõem. Os filhos-de-santo do Recife não poderiam, por motivos até ecológicos, seguir as mesmas receitas de seus predecessores da Nigéria e do Benim. ${ }^{9}$ Mas, do mesmo modo que seus antepassados, eles sabem que as folhas curam e purificam e que constituem, por conseguinte, a fonte primeira da saúde-santidade em que se encontra a finalidade suprema da iniciação. Ko si ewe, ko si orisa, se não há folha, não há orixá, diz-se, ainda hoje em dia, no Recife e em Salvador.

O Xangô e o Candomblé representam, para utilizar esta expressão weberiana, religiões intramundanas, embora não sejam absolutamente ascéticas. A graça dos deuses deve causar saúde, prosperidade, satisfação sexual e afetiva. Não há portanto santidade dissociada da saúde e do bem estar. E é nesta fusão que se encontra uma noção básica do Xangô e do Candomblé e mesmo, provavelmente, de toda a religião iorubá, na África e na diáspora americana. Trata-se do axé, que é força, saúde, santidade e felicidade. Sua fonte primeira é, como se acaba de assinalar, o sumo de certas folhas. Mas o axé também se encontra - e sobretudo se encontra - no sangue dos animais. De fato, em seguida ao amassi a iniciação afro-brasileira contínua com o assentamento. Este consiste na instalação do santo personalizado e individualizado do fiel numa pedra ou num pedaço de metal. O que só se se faz com grande derramamento de sangue animal, pois é preciso alimentar esses otás (altares). Depois, e é aí

9 Muitos livros e artigos têm se ocupado com o uso das folhas no Candomblé-Xangô. Um dos últimos grandes trabalhos de Verger (1995) foi expressamente dedicado ao uso das folhas na sociedade iorubá. 
que se encontra a culminância do percurso iniciático, faz-se a cabeça do noviço, através de certas incisões nas quais se colocam certos temperos, que são também portadores de axé e que se irriga com muito sangue animal, misturado ao sangue do próprio noviço, que deste modo vem a ser, a seu modo, alimento dos orixás.

O indivíduo terá então cumprido sua parte do contrato que o une ao santo. Se tudo foi bem realizado, se não houve negligência nem engano com relação ao orixá (porque pode acontecer dos búzios não terem sido bem interpretados), se se ofereceram os sacrifícios adequados, o devoto poderá esperar a remissão de seus males e a proteção do Alto na gerência de seu quotidiano e na resolução das crises de sua existência.

\section{Rezar e comer}

O útil sempre acompanha muito de perto o sagrado no Xangô. Apesar de todas as suas implicações ontológicas, o sacrifício não é somente bom para rezar ou para simbolizar. Na verdade, ele exerce funções muito práticas na vida dos fiéis e na economia da cidade do Recife. Ele possui, como se salientava acima, uma função terapêutica. Fortificando o santo, dono de sua cabeça, o homem se fortifica a si mesmo. Mas o sacrifício é também bom para comer. A religião afro-brasileira, com permissão do neologismo, é fagocêntrica. O que transparece já no vocabulário do povo-de-santo. Ao lado de obrigação, os fiéis empregam, para designar o sacrifício, o termo iorubá ebó, que quer dizer comida, além, simplesmente de, em bom vernáculo, comida.

Para excluir uma interpretação puramente simbólica do sacrifício, darei em seguida alguns exemplos derivados de meu trabalho de campo na área do Recife. Releio em meus cadernos o registro de uma grande matança em casa do falecido Mário Miranda, chefe, em Pernambuco, da nação Moçambique. ${ }^{10}$ Era véspera da festa de Ogum-São Jorge, coincidindo com o sétimo aniversário da iniciação de Iranete, filha-de-santo e prima bem-amada do babalorixá. Naquela tarde havia no terreiro mais bicho do que gente. Pelas minhas contas, foram dois carneiros, um bode, cinco cabras, um galo, duas pombas brancas, duas pombas cinzentas, além de uma multidão de galinhas e de frangos presos

${ }^{10} \mathrm{O}$ que não o impedia de seguir o rito nagô, isto é, iorubá, sem vestígio algum de influência das etnias moçambicanas. 
num gradil. Mário seguramente imolou, só naquela sessão, oito quadrúpedes e 35 aves, homenageando todos os santos do Xangô e até mesmo alguns caboclos da Jurema. ${ }^{11}$ À medida que iam sendo mortas, as vítimas eram transformadas em alimento, de que os devotos começaram a provar antes mesmo do término da cerimônia. Mário ficou no pegi, de onde, ao mesmo tempo em que degolava os bichos, entoava cânticos cheios de alusões à violência dos deuses e ao terror que inspiram nos animais e nos homens. Do lado de fora, respondia o coro das iabás, ${ }^{12}$ que também se ocupavam com a preparação da comida.

O sacrifício sangrento constitui a regra e não a exceção no contexto das religiões afro-brasileiras do Recife. Para continuar com exemplos, há a casa de Badia, que freqüentei durante quase quinze anos. Essa ilustre ialorixá fazia questão de oferecer, por ocasião dos ritos de outubro, a festa do inhame, sem dúvida a sobrevivência de um festival da colheita na terra dos iorubás, pelo menos 15 bichos de quatro patas e cerca de 45 pássaros, tudo isso imolado num quarto de menos de dez metros quadrados, de nove horas da manhã ao meio-dia. Aí se encontra a essência do Xangô: cabeças cortadas, cheiro de sangue, cânticos, passos de dança sobre o chão vermelho, alegria, êxtase.

Ko si edje, ko si orisa, se não há sangue, não há santo, pode-se ouvir de algum pai-de-santo mais conhecedor da língua nagô. ${ }^{13} \mathrm{E}$ o que muito bem havia compreendido o finado Zé Lins, o qual, quando de sua iniciação, não foi capaz de ofertar mais de duas cabras e duas galinhas. Da mesma forma Amara, cujos recursos limitados não lhe permitiram mais de duas cabras e dez galinhas, o que, decididamente era insuficiente, sobretudo porque também se tratava da inauguração de um novo terreiro. Foi inclusive difícil encontrar um pai-de-santo disposto a oficiar por tão pouco. Em compensação, Pai Edu, em

${ }^{11}$ A Jurema (ou Catimbó) é uma religião sincrética da área do Recife, dedicada principalmente ao culto de certos espíritos de origem vagamente indígena ou ibérica, caboclos e mestres, aos quais se acrescentam os ciganos e, mais recentemente, os exus, tais como reinterpretados pela Macumba carioca, e diversas outras categorias de espíritos. Em princípio, inclusive por causa da grande pobreza da maioria de seus adeptos, os sacrifícios de animais não são, ou pelo menos até pouco tempo não eram, praticados no Catimbó-Jurema.

${ }^{12}$ Sem ser propriamente secretos, os ritos do sacrifício só são presenciados, de modo geral, pelo sacrificante (isto é, na terminologia adotada por Hubert e Mauss (1899), aquele ou aquela que promove o sacrifício), seus próximos, o sacrificador (isto é, aquele que executa o sacrifício), alguns rapazes, que ajudam a abater e esquartejar as vítimas, e as iabás, as quais, na terminologia pernambucana, não são as orixás (Oxum, Iemanjá, etc.), mas as mulheres encarregadas da preparação da comida ritual.

${ }^{13}$ A língua nagô, conforme se sabe, é uma variedade de iorubá, que sobrevive no Brasil como língua litúrgica. 
seu período áureo, quando, graças a suas ligações com uma grande família recifense da qual era por assim dizer o capelão, ${ }^{14}$ tornou-se famoso em todo o Brasil, oferecia cerca de 500 frangos (e não levo em conta os quadrúpedes) em sua grande festa de agosto (em homenagem a Exu) e reunia, em torno de sua mesa, damas da alta sociedade, intelectuais de renome ${ }^{15}$ e grande quantidade de jornalistas. E a prática do sacrifício, longe de ir desaparecendo, como desejariam as interpretações evolucionistas das religiões afro-brasileiras, vêm, ao contrário, se intensificando nas últimas décadas do século XX.

É assim que, para a festa de Seu Viramundo, que também ocorre em agosto, Pai Raminho, em princípios da década de 80, matava um boi, dez caprinos e perto de 240 galináceos. Em 1989 convidou-me para assistir à imolação de três bois, a que eu, infelizmente, não pude comparecer. Já no dia 19 de agosto de 1991 fui testemunha da morte, em seu terreiro, de três cabritos, oferecidos às divindades infernais; no dia 24 vi três novilhos que acabavam de ser degolados em seu salão de dança; sem contar com o convite para que eu também assistisse, alguns dias depois, ao abate de outro novilho, destinado ao orixá Xangô, que é, acredita-se, o dono de minha cabeça. ${ }^{16} \mathrm{E}$ não falo da multidão de bichos menores, frangos, galinhas e patos, sacrificados durante aquelas celebrações, que a cada ano parece que se tornam mais grandiosas.

Na repartição das carnes o Xangô estabelece uma oposição entre o axé, composto do sangue, do coração e de alguns outros órgãos, e o eran, compreendendo essencialmente as carnes vermelhas. O primeiro, em princípio, é reservado aos orixás. Colocado sobre os altares - com todos os efeitos de decomposição que se pode imaginar, inclusive olfativos - depois de alguns dias é despachado, levado para fora do mundo, entregue aos orixás em algum lugar apropriado, no mato, na água ou, em certos casos, nas encruzilhadas.

Já o eran é consumido pelos fiéis em ocasiões encaradas como puramente profanas. Poderíamos identificar, no funcionamento do Xangô, um sistema de troca generalizada. ${ }^{17} \mathrm{~A}, \mathrm{~B}$ e C compartilham o sacrifício oferecido por D.

\footnotetext{
${ }^{14}$ A família P. de Q., que se entroncava com a aristocracia do açúcar de Pernambuco e estados vizinhos, era, em seu período áureo, proprietária de vários jornais, emissoras de rádio e de um canal de televisão.

${ }^{15}$ Entre esses intelectuais, Gilberto Freyre, o autor de maior prestígio em Pernambuco.

${ }^{16}$ Influenciado por reinterpretações relativamente recentes do Candomblé, provenientes da área do Rio de Janeiro, Raminho apresenta forte tendência ao kitsch e ao colossal, que parecem caracterizar o ethos das regiões mais modernizadas do Brasil. Os sacrifícios do ano de 1991, realizados em casa desse ilustre babalorixá, foram também descritos por um colega francês (Ferreux, 1993).

${ }^{17}$ Esta noção de troca generalizada é devida a Lévi-Strauss (1949).
} 
Este, com B e C, participa do oferecimento de E, o qual, com A e F, se beneficia das ofertas de $\mathrm{B}$ e assim por diante. Mas convém observar que esse belo modelo de reciprocidade encontra-se viciado por várias contradições. Há em primeiro lugar a alternância entre períodos de vacas gordas e de vacas magras, muitas vezes influenciada pelas oscilações da economia brasileira. Ainda mais importante, a própria organização do Xangô cria desigualdades. Na qualidade de proprietários dos meios da produção simbólica, sacerdotes e sacerdotisas exigem e recebem um benefício que está longe de ser puramente simbólico. Eles ficam com a parte do leão... Além disso, os membros da hierarquia podem favorecer alguns participantes em detrimento de outros. Basta que em casa de tal ou qual babalorixá ou ialorixá haja, por ocasião das festas, menos lugares à mesa, menos pratos, menos talheres do que assistentes... Os fiéis, de modo geral, não contestam as decisões dos superiores, pois compreendem perfeitamente que (de modo parecido ao que ocorre na carreira universitária) uma atitude obediente e conformada pode ajudar na ascensão aos mais altos postos, enquanto queixas e protestos podem fazer com que sejam excluídos e marginalizados.

\section{0 mais-que-sagrado}

Entre os filhos-de-santo o sacrifício, como já se salientou, desempenha funções de caráter muito prático, que podem, à sua maneira, ser estudadas até mesmo por economistas. O sacrifício alimenta os homens. Mas ele também alimenta os santos, os quais, sem ele, simplesmente seriam incapazes de agir e de aparecer. Mas para que isto ocorra, é preciso um dom suplementar, que é o do próprio corpo dos fiéis. Trata-se, noutras palavras, do transe, que não é simplesmente constituído, como no espiritismo, de uma outra personalidade que, manifestando-se através de seu próprio discurso, substituí a personalidade normal do fiel, mas da superação do discurso, através de uma intuição que nenhum conceito, nem mesmo o de um deus, é capaz de exprimir.

Chegamos ao terreno da festa, que não precisa se justificar por nenhum serviço que prestaria, nenhuma função que desempenhasse no plano social, cultural ou psicológico. Este mais-que-sagrado ${ }^{18}$ não se limita a significar a solidariedade social, a realização simbólica do desejo, a inversão das

${ }^{18}$ A expressão mais-que-sagrado é devida ao filósofo italiano Mario Perniola (1992). 
hierarquias ou o retorno à Africa concebido como uma espécie de sionismo místico. Estamos aqui situados além da concepção funcionalista do sagrado, sugerida, de maneira sem dúvida grandiosa, por Emile Durkheim e retomada, com menos brio, por Radcliffe-Brown e sua escola de Antropologia Social, concepção cuja parte de verdade não se pretende aqui absolutamente negar.

O sacrifício e a iniciação pareceriam indicar, entre os afro-brasileiros, que o sagrado e o profano, o sagrado e o quotidiano, aproximam-se até demais. Não representam, como quereria uma interpretação demasiadamente literal de Durkheim, ${ }^{19}$ duas categorias de coisas sempre e radicalmente opostas uma à outra. Mas existe, na religião, como o grande sociólogo, em outras palavras, soube muito bem reconhecer, um momento, o mais-que-sagrado ou ultra-sagrado, ${ }^{20}$ que, como o transe extático e intuitivo do Xangô, não serve enfim para nada além de si mesmo ${ }^{21}$ e é bom para existir.

\section{Jorro de identidade}

Nas tardes de domingo, quando estou no Recife, gosto de caminhar pelo bairro de Beberibe, entre o rio e os morros, que era, quando comecei a fazer meu trabalho de campo em 1974, que ainda é, a grande reserva biológica e cultural do Xangô de Pernambuco. Eu constato, com certa tristeza, que a modernidade avançou muito por essa área, nos últimos 20 ou 25 anos. Abriramse avenidas, uma das grandes perimetrais do Recife passa hoje em dia pelo centro desse bairro, acarretando a intrusão de cabarés, danceterias, boates. Vejo muitos conjuntos residenciais (como se veem em toda parte, inclusive na Europa Oriental). Nesses domingos, eu encontro muitos alto-falantes, transmitindo o que há de mais kitsch na música nacional e internacional. Só paro de escutar uma dessas máquinas infernais quando começo a escutar outra. Aí eu estou muitos anos-luz distanciado de meus terreiros. Porque não existe

${ }^{19}$ O próprio Durkheim (1985, p. 545) parece superar todo funcionalismo ao escrever, por exemplo, que “o estado de efervescência em que se encontram os fiéis reunidos traduz-se necessariamente por movimentos exuberantes [...] correspondendo simplesmente à necessidade de agir, de mover-se, de gesticular, experimentada pelos fiéis. Estes saltam, giram, gritam, dançam, cantam, sem que sempre seja possível atribuir sentido a essa agitação.”

20 Tal como o emprego - e creio que esse é também o caso de Mario Perniola - o conceito de mais-que-sagrado ou de ultra-sagrado aproxima-se da concepção do santo em Otto (1949), retomada, apesar de algumas diferenças de interpretação, por Lowie (1924) e, mais recentemente, por Berger (1969).

${ }^{21}$ Sobre a festa e o transe que não servem para nada, ver Duvignaud (1973). 
relacionamento possível entre, de uma parte, esse kitsch dominical, essas pessoas que são afetadas pela modernidade mas que não conseguem participar de sua dinâmica, essas pessoas que dançam como, em bairros do mesmo nível, as pessoas dançam em Paris, Londres e Nova Iorque e que me dão a impressão de representar caricaturas da ultra-modernidade e, de outro lado, as congregações do Xangô, com sua música séria, grave e, a seu modo, trágica, descrevendo a condição humana em sua contingência, sua precariedade, sua fragilidade ontológica. Esta música jorra daquilo que um povo possui de mais profundo e de mais íntimo.

Aí eu me lembro de um filho-de-santo chamado Manuel, faz muitos anos. Releio minhas notas. Giz de várias cores lançado na água esverdeada pelo sumo das folhas. Manuel batizado com esse amassi. Toadas de Iemanjá, passos de dança. Uma alegria sem limites toma conta dos circunstantes. É a culminância do Xangô, esta reunião íntima, a portas fechadas. E é longe dos olhares estranhos que a pequena congregação vibra na afirmação de sua verdade. Cada uma das pessoas possui o seu segredo, revelado entre outros segredos. E um diamante jamais exposto à luz do dia: "Ele pende da face da noite como uma jóia preciosa, pendurada na orelha de um etíope.”22

Os rostos se transfiguram. Iemanjá também é dos homens, que marcam. seu ritmo nas caixas de fósforos e na madeira da mesa. Todos se levantam quando Das Dores, marejada com a santa, oscila, levando de volta ao pegi as insígnias sagradas. Depois é a vez de Obaluaê. Quatro flechas de estanho representam seu assentamento, digno sinal de "Apolo, que fere de longe”.

Eu me lembro e compreendo. Quaisquer que sejam as restrições que, como discípulo ingrato, eu queira fazer à sociologia de Durkheim, é ele que tem razão. A identidade, esse nome secreto. que carregamos, vem dessa comunidade que não é mais do que partilha de emoção. A emoção com que nós nos reconhecemos. E aí compreendo como, eu próprio, fui encontrar minha identidade em Beberibe, E compreendo como a religião africana, a religião dos analfabetos, pôde transformar-se numa das principais fontes de orientação e identidade do povo brasileiro, sem distinção de cor nem de origem étnica.

${ }^{22}$ Shakespeare, Romeu e Julieta, ato I, cena V. 


\section{Referências}

BERGER, P. The sacred canopy. New York: Doubleday, 1969.

DURKHEIM, E. Les formes elémentaires de la vie religieuse. Paris: Presses Universitaires de France, 1985.

DUVIGNAUD, J. Fêtes et civilisations. Genève: Wébert, 1973.

FERREUX, J. Possessions à Recife. Galaxie Anthropologique, n. 45, p. 5358, 1993.

HERSKOVITS, M. Some economie aspects of the Afrobahian Candomblé. In: HERSKOVITS, M. The New World negro. Bloomington: Indiana University Press, 1958. p. 248-266.

HUBERT, H.; MAUSS, M. Essai sur la nature et la fonction du sacrifice. L’Année Sociologique, n. 2, p. 29-138, 1899.

LA PORTA, E. Estudo psicanalítico dos rituais afro-brasileiros. Rio de Janeiro: Livraria Ateneu, 1979.

LÉVI-STRAUSS, C. Les structures elémentaires de la parenté. Paris: Presses Universitaires de France, 1949.

LÉVI-STRAUSS, C. Le totémisme aujourd'hui. Paris: Presses Universitaires de France, 1962.

MOTTA, R. Comida, família, dança e transe. Revista de Antropologia, São Paulo, v. 25, p. 147-158, 1982.

MOTTA, R. Meat and feast: the Xangô religion of Recife, Brazil. 1988. Tese (Doutorado em Antropologia)-Department of Anthropology, Columbia University in the City of New York, New York, 1988.

MOTTA, R. Edjé balé: alguns aspectos do sacrifício no Xangô de Pernambuco. 1991. Tese de concurso para professor-titular de Antropologia na Universidade Federal de Pernambuco. Recife, 1991a. 
MOTTA, R. Transe du corps et transe de la parole dans les religions syncrétiques du Nordest du Brésil. Cahiers de l'Imaginaire, Paris: L’Harmattan, n. 5-6, 1991b.

MOTTA, R. Ethnicité, nationalité et syncrétisme dans les religions populaires brésiliennes. Social Compass, v. 41, n. 1, p. 67-78, 1994.

OTTO, R. Le sacré. Paris: Payot, 1949.

PERNIOLA, M. Più-che-sacro, più-che-profano. Milano: Mimesis, 1992.

RAMOS, A. O negro brasileiro. Rio de Janeiro: Civilização Brasileira, 1940.

RIBEIRO, R. Cultos afro-brasileiros do Recife. Recife: Massangana, 1978.

SANTOS, J. E. dos. Os nagô e a morte. Petrópolis: Vozes, 1976.

VERGER, P. Ewé: o uso das plantas na sociedade iorubá. São Paulo: Companhia da Letras, 1995.

WEBER, M. Economie et société. Paris: Plon, 1995.

WILLIAMS, P. V. A. Primitive religion and healing: a study of folk medicine in Northeast Brazil. Cambridge: Brewer for the Folklore Society, 1979. 